\title{
Causes of Persistent Dizziness in Elderly Patients in Primary Care
}

\author{
Otto R. Maarsingh, $M D^{1}$ \\ Jacquelien Dros, $M D^{2}$ \\ François G. Schellevis, $M D, P b D^{1,3}$ \\ Henk C. van Weert, MD, $P b D^{2}$ \\ Danielle A. van der Windt, PbD ${ }^{1,4}$ \\ Gerben ter Riet, $M D, P b D^{2}$ \\ Henriette E. van der Horst, MD, PbD ${ }^{1}$ \\ 'Department of Family Practice and \\ EMGO Institute for Health and Care \\ Research, VU University Medical Center, \\ Amsterdam, The Netherlands \\ ${ }^{2}$ Department of Family Practice, Academic \\ Medical Center, University of Amsterdam \\ Amsterdam, The Netherlands \\ ${ }^{3}$ NIVEL, The Netherlands Institute \\ for Health Services Research, Utrecht, \\ The Netherlands \\ ${ }^{4}$ Primary Care Sciences Research Centre, \\ Keele University, Keele, Staffordshire, \\ England
}

AC Annals Journal Club selection; see inside back cover or http://www. annfammed.org/AJC/.

Conflicts of interest: none reported

\section{CORRESPONDING AUTHOR}

Otto R. Maarsingh, MD

Department of Family Practice and Institute for Research in Extramural Medicine VU University Medical Center (D556) Van der Boechorststraat 7 1081 BT Amsterdam, The Netherlands o.maarsingh@vumc.nl

\begin{abstract}
PURPOSE Although dizzy patients are predominantly seen in primary care, most diagnostic studies on dizziness have been performed among patients in secondary or tertiary care. Our objective was to describe subtypes of dizziness in elderly patients in primary care and to assess contributory causes of dizziness.
\end{abstract}

METHODS We performed a cross-sectional diagnostic study among elderly patients in the Netherlands consulting their family physician for persistent dizziness. All patients underwent a comprehensive evaluation according to a set of diagnostic tests that were developed during an international Delphi procedure. Data for each patient were independently reviewed by a panel consisting of a family physician, a geriatrician, and a nursing home physician, which resulted in major and minor contributory causes of dizziness.

RESULTS From June 2006 to January 2008, we included 417 patients aged 65 to 95 years. Presyncope was the most common dizziness subtype (69\%). Forty-four percent of the patients were assigned more than 1 dizziness subtype. Cardiovascular disease was considered to be the most common major contributory cause of dizziness (57\%), followed by peripheral vestibular disease (14\%), and psychiatric illness (10\%). An adverse drug effect was considered to be the most common minor contributory cause of dizziness (23\%). Sixty-two percent of the patients were assigned more than 1 contributory cause of dizziness.

CONCLUSIONS Contrary to most previous studies, cardiovascular disease was found to be the most common major cause of dizziness in elderly patients in primary care. In one-quarter of all patients an adverse drug effect was considered to be a contributory cause of dizziness, which is much higher than reported in previous studies.

Ann Fam Med 2010;8:196-205. doi:10.1370/afm.1116.

\section{INTRODUCTION}

$\mathrm{D}$ izziness is common in elderly people $30 \%$ of people older than 65 years experience dizziness in some form ${ }_{1}^{1-4}$ increasing to $50 \%$ in the very old (older than 85 years).' For clinicians, dizziness often represents a diagnostic problem: it is a subjective sensation that depends on self-report, it may refer to several different and overlapping sensations, and it can be caused by a wide range of benign or serious conditions. ${ }^{5,6}$ In $20 \%$ to $40 \%$ of dizzy patients in primary care, the underlying cause remains unknown. ${ }^{7-9}$

Patients with dizziness are managed largely at primary care level. ${ }^{10}$ From 1985 to 1995 , Dutch family physicians referred only 3\% of dizzy elderly patients to a medical specialist. ${ }^{11}$ Most diagnostic studies on dizziness, however, have been performed among patients seen in emergency departments ${ }^{8,12,13}$ or in a secondary or tertiary care setting. ${ }^{5,14-19}$ Because of selective referral, the distribution of diagnoses in secondary and tertiary care patients is probably different from patients in primary care (spectrum variation). This skewed distribution hampers the application of findings from secondary and tertiary care research to patients in primary care. The 
objective of this study was to describe subtypes of dizziness in elderly patients in primary care and to assess the contributory causes of dizziness.

\section{METHODS}

\section{Setting and Patients}

Participants were recruited among consecutive patients seen by 45 family physicians in 24 Dutch family practices. Patients aged 65 years or older consulting their family physician for dizziness that had been present for at least 2 weeks were invited to participate. Additionally, each month the electronic databases of all practices were searched retrospectively for any dizzy patients the family physicians had failed to invite (Supplemental Appendix 1, available at http://annfammed.org/cgi/ content/full/8/3/196/DC1). These patients received a written invitation to participate in the study. Informed consent was obtained from all participants. Our definition of dizziness included a giddy or rotational sensation, a loss of balance, a faint feeling, light-headedness, instability or unsteadiness, a tendency to fall, or a feeling of everything turning black. ${ }^{6}$ Criteria for exclusion were the inability to speak Dutch or English, severe cognitive impairment, severe visual impairment (ie, corrected visual acuity of less than 3/60 [Snellen metric] in the best eye), severe hearing impairment (ie, verbal communication impossible), or wheelchair dependency.

Patients were enrolled from June 2006 to January 2008, and the study protocol was approved by the Medical Ethics Committee of the VU University Medical Center.

\section{Evaluation}

All patients underwent a standardized, comprehensive evaluation based on a set of diagnostic tests that were developed during an international Delphi procedure. ${ }^{20}$ The patients were examined in a family practice setting by 2 study authors (O.R.M., J.D.) and 3 well-trained physicians. Patients not able to visit the practice for medical reasons were examined at home.

\section{Medical History}

We recorded sociodemographic characteristics, smoking habits, alcohol intake, current medication use (including the use of fall-risk-increasing drugs [FRID]), ${ }^{21,22}$ medical history, characteristics of dizziness, and the use of a hearing, seeing, or walking aid. All patients had to complete the Primary Care Evaluation of Mental Disorders (PRIME-MD) Patient Health Questionnaire (PHQ), a self-administered instrument to assess psychiatric disorders, ${ }^{23,24}$ and the Dizziness Handicap Inventory, a questionnaire used to quantify the impact of dizziness on everyday life. ${ }^{25}$

\section{Physical Examination and Additional Diagnostic Tests}

Diagnostic criteria are displayed in Supplemental Appendix 2, available at http://annfammed.org/ cgi/content/full/8/3/196/DC1. Cardiovascular examination consisted of measurement of pulse and blood pressure, the orthostatic hypotension test, and auscultation of the heart. For the orthostatic hypotension test we measured blood pressure after 5 minutes in supine position, then measured it again in a standing position after $1,2,3,4$, and 5 minutes. ${ }^{26,27}$ Additional cardiovascular assessment was performed on indication. Electrocardiography (ECG) was indicated if (1) a patient complained of presyncopal dizziness (faint feeling, light-headedness, or feeling everything turning black), (2) dizziness was accompanied by palpitations, or (3) exercise provoked complaints of dizziness. Patient-activated continuous-loop event recording (CER) was indicated if an ECG did not indicate a clear explanation. ${ }^{28}$ For financial reasons, we only performed CER for the first 60 such consecutive patients.

Evaluation of the locomotor system consisted of orthopedic screening of the lower limbs, tandem gait, ${ }^{29}$ and the timed up-and-go test (a test used to quantify functional mobility). ${ }^{30}$ Neurological evaluation consisted of examination of tendon reflexes and the Semmes-Weinstein monofilament test (5.07/10 g) to detect peripheral neuropathy. ${ }^{31-33}$ Evaluation of the vestibular system consisted of otoscopy, the Dix-Hallpike maneuver, ${ }^{34-36}$ and audiometry. ${ }^{37}$ Visual acuity was measured by means of a well-lit eye chart with Landolt rings. Laboratory evaluation included the measurement of hemoglobin level ${ }^{38}$ and non-fasting blood glucose. ${ }^{39}$

\section{Determination of Subtype and Cause of Dizziness}

To reduce investigator bias, we asked a panel of clinicians to assign subtype(s) and cause(s) of dizziness to all patients. ${ }^{9}$ Data for each patient (including medical history, physical examination, and additional diagnostic tests) were recorded on a standardized form, which was independently reviewed by 3 clinicians representing different medical disciplines: a family physician, a geriatrician, and a nursing home physician. The reviewers did not meet to avoid domination by 1 of the reviewers. ${ }^{40}$ For each patient, the panel was asked to assess the dizziness subtype(s), and the contributory cause(s) of dizziness (in predefined categories as well as in words). Supplemental Appendix 3, available at http:// annfammed.org/cgi/content/full/8/3/196/DC1 shows the score form used by the reviewers.

First, the reviewers assigned a predefined dizziness subtype to each patient, either vertigo, presyncope, disequilibrium, other dizziness, or a (specified) 
combination of subtypes. ${ }^{6,15}$ After all patients had been assessed, we assigned a definite dizziness subtype, or combination of subtypes, to each patient by means of a majority decision (at least 2 of the 3 reviewers had to agree). Second, the reviewers estimated the relative contribution (from $0 \%$ to $100 \%$ ) of 9 categories of possible causes of dizziness ${ }^{6,15,41-43}$ : (1) adverse drug effect, (2) cardiovascular disease (including cerebrovascular disease), (3) locomotor disease, (4) metabolic or endocrine conditions, (5) neurological disease (excluding cerebrovascular disease), (6) psychiatric illness, (7) peripheral vestibular disease, (8) impaired vision, and (9) other causes. The contribution of each of the 9 causes was calculated as a mean percentage across the 3 reviewers, with the restriction that a cause could contribute only if at least 2 reviewers estimated the relative contribution to be more than $0 \%$. For each patient we considered the cause with the highest mean percentage to be the major cause, whereas all other causes with a mean percentage of at least $10 \%$ were considered minor causes. Causes with a mean percentage of less than $10 \%$ were considered noncontributing.

Finally, we asked the panel to describe in words the most probable cause of dizziness.

For each patient, we compared these descriptions with the final results regarding categories of contributing causes. If the calculated major causes were not sufficiently covered by the descriptions of at least 2 of 3 reviewers, the cause of dizziness was considered to be unclear.

\section{Statistical Analysis}

Descriptive statistics were calculated to characterize the study population and to describe the distribution of subtypes and causes of dizziness. Interrater agreement for classifying the subtype of dizziness was determined by calculating Cohen's $\kappa$ for more than 2 annotators with multiple classes. ${ }^{44}$ Interrater agreement for the estimated contribution ( $0 \%$ to $100 \%)$ of causes of dizziness was determined by calculating the intraclass correlation coefficient (ICC) for consistency, using a 2-way random effects model for single measurements. ${ }^{45}$ Values of interrater agreement were interpreted according to Landis and Koch. ${ }^{46}$

To assess the robustness of the threshold for contributing causes of dizziness (set at 10\%), we performed a sensitivity analysis, with alternative thresholds set at $7.5 \%, 15 \%, 20 \%$, and $25 \%$.

\section{RESULTS}

\section{Patient Characteristics}

During the 19 -month study period 417 patients completed the diagnostic evaluation. In 10 patients the diz-

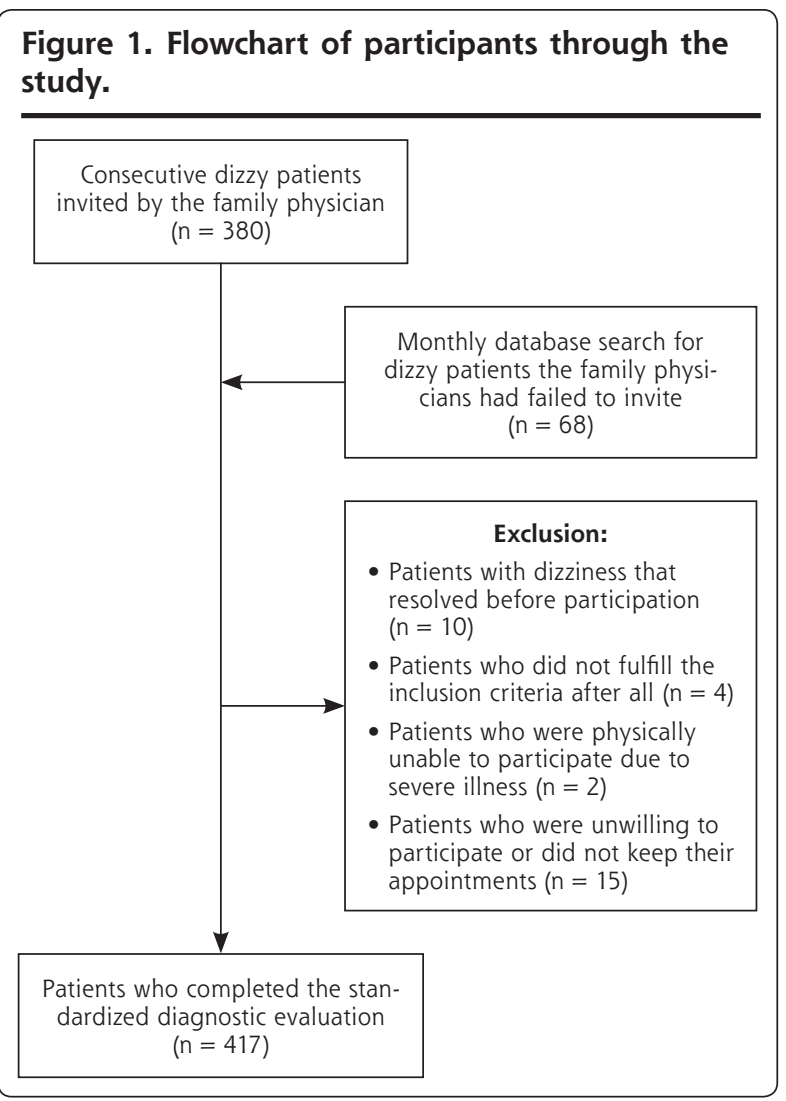

ziness had already resolved. Four patients did not fulfill the inclusion criteria, 2 patients were physically unable to participate, and 15 patients refused or did not keep their appointments (Figure 1).

Patient characteristics are displayed in Table 1, and dizziness characteristics are displayed in Table 2 . The mean impact of dizziness on everyday life, as measured by the Dizziness Handicap Inventory on a scale from 0 to 100 , with 0 indicating the least impact, was 36.3 $(\mathrm{SD} \pm 19.9)$

Table 3 shows the frequency of abnormal findings during physical examination and additional diagnostic tests. Frequent abnormal test results (40\% to $50 \%$ of the patients) included an abnormal Semmes-Weinstein monofilament test, high systolic blood pressure, abnormal audiometry for both ears, limited stability at rest and during walking, and at least 1 psychiatric disorder according to the PRIME-MD PHQ.

\section{Subtypes and Causes of Dizziness}

According to the panel, presyncope was the most common dizziness subtype (69\%), after which came vertigo (41\%), disequilibrium (40\%), and other dizziness (2\%). Forty-four percent of the patients were assigned 2 or 3 dizziness subtypes. The panel members did not agree on the dizziness subtype(s) of 16 patients (Table 4 ). 


\begin{tabular}{|c|c|c|c|}
\hline Characteristic & Value & Characteristic & Value \\
\hline Sex, female, No. (\%) & $307(74)$ & Medical history & \\
\hline Age, mean (range), y & $78.5(65-95)$ & Cardiovascular disease, No. (\%) & \\
\hline Living situation, No. (\%) & & Hypertension & $239(57)$ \\
\hline Alone & $254(61)$ & Ischemic heart disease & $111(27)$ \\
\hline Home for the elderly, or other institution & $66(16)$ & Arrhythmia & $94(23)$ \\
\hline Ethnic background, No. (\%) & & Heart valve disease & $58(14)$ \\
\hline Dutch native & $342(82)$ & Myocardial infarction & $57(14)$ \\
\hline Western immigrant & $31(7)$ & Ear, nose, and throat disease, No. (\%) & \\
\hline Non-Western immigrant & $44(11)$ & Benign paroxysmal positional dizziness & $40(10)$ \\
\hline Level of education, No. (\%) & & Ménière's disease & $27(6)$ \\
\hline Elementary school & $119(29)$ & Acoustic neuroma & $1(0.2)$ \\
\hline High school & $247(59)$ & Neurological disease, No. (\%) & \\
\hline College/university & $51(12)$ & Migraine & $79(19)$ \\
\hline Smoking, No. (\%) & $62(15)$ & Cerebrovascular disease & $66(16)$ \\
\hline Drugs, total. & & Parkinson disease & $7(2)$ \\
\hline Drugs per patient, mean (SD), No. & $4.4(3.0)$ & Epilepsy & $6(1)$ \\
\hline Polypharmacy (patients using $>5$ drugs), No. $\%^{21}$ & $138(33)$ & Multiple sclerosis & $1(0.2)$ \\
\hline Fall-risk-increasing drugs (FRID) ${ }^{22}$ & & Locomotor disease, No. (\%) & \\
\hline FRID per patient, mean (SD), No. & $1.9(1.5)$ & Arthrosis of the knee (gonarthrosis) & $120(29)$ \\
\hline Patients using $\geq 3$ FRID, No. (\%) & $154(37)$ & Arthrosis of the hip (coxarthrosis) & 78 (19) \\
\hline Distribution of FRID, No. (\%) & & Psychiatric illness, No. (\%) & \\
\hline Diuretics & $149(36)$ & Depressive disorder & $101(24)$ \\
\hline$\beta$-Blockers & $128(31)$ & Anxiety disorder & $75(18)$ \\
\hline Calcium channel blockers & $80(19)$ & Other, No. (\%) & \\
\hline Angiotensin receptor blockers & $71(17)$ & Cataract & $199(48)$ \\
\hline Angiotensin converting enzyme inhibitors & $67(16)$ & Diabetes & $78(19)$ \\
\hline Anxiolytics/hypnotics & $52(12)$ & Macular degeneration & $27(7)$ \\
\hline Nitrates & $51(12)$ & & \\
\hline Hypoglycemics & $48(12)$ & & \\
\hline Antidepressants & $35(8)$ & & \\
\hline Antivertigo drugs & $31(7)$ & & \\
\hline Analgesics & $25(6)$ & & \\
\hline$\alpha$-Blockers & $21(5)$ & & \\
\hline Neuroleptics & $16(4)$ & & \\
\hline Antiarrhythmics & $15(4)$ & & \\
\hline Digoxin & $13(3)$ & & \\
\hline Antihistamines & $11(3)$ & & \\
\hline
\end{tabular}

According to the panel, cardiovascular disease was the most common major contributory cause of dizziness $(57 \%)$, then peripheral vestibular disease $(14 \%)$, and psychiatric illness (10\%). An adverse drug effect was considered to be the most common minor contributory cause of dizziness (23\%). Sixty-two percent of the patients were assigned 2 or more contributory causes. The panel members did not agree on the cause of dizziness in 34 patients (Table 5).

When performing the sensitivity analysis, raising the threshold gradually increased the relative contribution of cardiovascular disease, while it decreased the relative contribution of an adverse drug effect. Raising the threshold did not affect the relative contribution of other causes of dizziness. Lowering the threshold did not affect the relative contribution of any of the 9 possible causes of dizziness.

\section{Interrater Agreement}

Interrater agreement for the assignment of dizziness subtypes was highest for the subtype vertigo $(\kappa=0.4$, moderate agreement), then presyncope and disequilibrium ( $\kappa=0.3$, fair agreement), and other dizziness $\left(\kappa=0.1\right.$, slight agreement) ${ }^{46}$ Interrater agreement for assessment of contributing causes of dizziness was best for metabolic or endocrine conditions, psychiatric illness, and peripheral vestibular disease (ICC $=0.4)$, followed by cardiovascular disease and locomotor disease $($ ICC $=0.3)$, adverse drug effect and impaired vision $(\mathrm{ICC}=0.2)$, and neurological disease $(\mathrm{ICC}=0.1)$. 


\begin{tabular}{|c|c|c|c|c|c|}
\hline Characteristic & No. & $\%$ & Characteristic & No. & $\%$ \\
\hline \multicolumn{3}{|l|}{ Description ${ }^{\mathrm{a}}$} & \multicolumn{3}{|l|}{ Provoking circumstances ${ }^{\mathrm{a}}$} \\
\hline Instability or unsteadiness & 287 & 69 & \multirow{2}{*}{$\begin{array}{l}\text { Getting up from a lying or sitting } \\
\text { position }\end{array}$} & \multirow[t]{2}{*}{292} & \multirow[t]{2}{*}{70} \\
\hline Loss of balance & 280 & 67 & & & \\
\hline Light-headedness & 248 & 59 & Bending forward & 258 & 62 \\
\hline Rotational sensation & 228 & 55 & Turning head & 223 & 53 \\
\hline Tendency to fall & 226 & 54 & Looking up & 210 & 50 \\
\hline Giddy & 176 & 42 & Exercise & 140 & 34 \\
\hline Environment spinning & 137 & 33 & Standing still & 99 & 24 \\
\hline Becoming unwell & 115 & 28 & Strong emotions & 82 & 20 \\
\hline Near faint & 97 & 23 & Other & 109 & 26 \\
\hline Everything turning black & 68 & 16 & None & 17 & 4 \\
\hline Other dizziness & 83 & 20 & \multicolumn{3}{|l|}{ Associated symptoms ${ }^{\mathrm{a}}$} \\
\hline \multicolumn{3}{|l|}{ Onset } & Falling/almost falling & 207 & 50 \\
\hline $2-4 w k$ & 30 & 7 & Trouble with walking & 184 & 44 \\
\hline $1-6 \mathrm{mo}$ & 98 & 24 & Nausea & 112 & 27 \\
\hline $6-24 \mathrm{mo}$ & 110 & 26 & Sweaty, pale, or clammy & 91 & 22 \\
\hline $2-10 y$ & 120 & 29 & Fear & 82 & 20 \\
\hline$>10 y$ & 59 & 14 & Dyspnea & 48 & 12 \\
\hline \multicolumn{3}{|l|}{ Duration of symptoms } & Tinnitus & 42 & 10 \\
\hline$<10 \mathrm{sec}$ & 110 & 26 & Palpitations & 41 & 10 \\
\hline $10-60 \mathrm{sec}$ & 78 & 19 & Chest pain & 28 & 7 \\
\hline Several minutes & 71 & 17 & Diplopia & 27 & 6 \\
\hline Several minutes to $1 \mathrm{~h}$ & 22 & 5 & Hearing problems & 24 & 6 \\
\hline$>1 \mathrm{~h}$ & 35 & 8 & Trouble with speaking or swallowing & 12 & 3 \\
\hline Constant when present & 26 & 6 & Other & 57 & 14 \\
\hline Combination of above possibilities & 75 & 18 & None & 110 & 26 \\
\hline \multicolumn{3}{|l|}{ Frequency } & Chest pain & 28 & 7 \\
\hline Continuous & 42 & 10 & & & \\
\hline Daily & 195 & 47 & & & \\
\hline Weekly & 105 & 25 & & & \\
\hline Monthly & 50 & 12 & & & \\
\hline Annually & 25 & 6 & & & \\
\hline
\end{tabular}

Panel members tended to have a preference for diagnostic categories, such as cardiovascular disease (nursing home doctor, 63\%, family physician, 35\%, and geriatrician, 44\%), adverse drug effect (geriatrician, $16 \%$, family physician, $12 \%$, and nursing home doctor, 5\%), and psychiatric illness (family physician, $14 \%$, geriatrician, $9 \%$, and nursing home doctor, $8 \%$ ).

\section{DISCUSSION}

According to the panel, presyncope was the most common dizziness subtype in dizzy elderly patients in primary care. Forty-four percent of the patients were assigned more than 1 dizziness subtype. Cardiovascular disease was considered to be the most common major contributory cause of dizziness (57\%), with peripheral vestibular disease (14\%) and psychiatric illness $(10 \%)$ coming next. An adverse drug effect was considered to be the most common minor contributory cause of dizziness (23\%). Sixty-two percent of the dizzy patients were assigned more than 1 contributory cause of dizziness

\section{Comparison With Existing Literature}

Although dizzy patients are predominantly seen in family practice, ${ }^{10,11}$ only few diagnostic studies on dizziness have been performed among patients seen in a family practice setting. ${ }^{7,47,48}$ Most studies have been performed among patients not representative of family practice $e^{5,8,12-19}$ or less representative of family practice, such as those by Colledge et al (community-based population) ${ }^{49}$ or Kroenke et al (mixed hospital population). ${ }^{9}$

Previous studies often reported vertigo as the most common subtype of dizziness, varying from $40 \%$ to $55 \%$ of the studied population. These studies, however, included a younger ${ }^{9,47}$ or referred population. ${ }^{5,15}$ 
In our study $44 \%$ of the patients were assigned more than 1 dizziness subtype, which is consistent with the results of other studies on dizziness in elderly people. ${ }^{2,49}$

Cardiovascular disease was considered to be the most common cause of dizziness in elderly patients, which is consistent with previous reports of Colledge et $\mathrm{al}^{49}$ and Lawson et al. ${ }^{7}$ Kroenke and coworkers reported vestibular disease to be the most common cause of dizziness, ${ }^{9}$ perhaps the result of a different setting (hospital vs family practice in our study) and a different age of the study population (mean, 62 years vs 79 years in our study). Several other studies also reported vestibular disease to be the most common cause of dizziness.

Again, this finding may be due to differences in setting or patient selection, resulting in a younger population, ${ }^{47,48}$ a vertiginous population, ${ }^{47}$ a population seen in emergency departments, ${ }^{8,12,13}$ or a referred population..$^{5,14-19}$

The use of drugs in our study population was high; $33 \%$ of the dizzy patients used more than 5 drugs, and $37 \%$ used 3 or more fall-risk-increasing drugs. According to our panel, an adverse drug effect was considered to be a (major or minor) contributory cause in $25 \%$ of the dizzy patients. This rate was much higher than reported in previous studies, varying from 1\%-9\%..$^{5,8,12,14,48}$ This difference may be partially explained by the older age of our study population. It is possible, however, that previous investigators may have underestimated the contribution of drugs as a cause of dizziness in elderly patients, because they only registered a small selection of all potentially dizziness causing drugs. ${ }^{5,8,12,14,48}$

Finally, when comparing previous literature on dizziness,
Table 3. Abnormal Findings During the Examination of 417 Dizzy Elderly Patients in Primary Care

\begin{tabular}{|c|c|c|c|}
\hline Examination by System & Findings & No. & $\%$ \\
\hline \multicolumn{4}{|l|}{ Physical examination } \\
\hline \multicolumn{4}{|l|}{ Cardiovascular system } \\
\hline \multirow[t]{3}{*}{ Pulse } & Bradycardia & 23 & 6 \\
\hline & Tachycardia & 1 & 0 \\
\hline & Irregular & 50 & 12 \\
\hline Blood pressure & Systolic blood pressure $\geq 160 \mathrm{~mm} \mathrm{Hg}$ & 198 & 48 \\
\hline \multirow{3}{*}{$\begin{array}{l}\text { Orthostatic hypotension } \\
\text { test }\end{array}$} & Positive, without reproduction of symptoms & 43 & 10 \\
\hline & Positive, with reproduction of symptoms & 58 & 14 \\
\hline & Unknowna & 5 & 1 \\
\hline \multirow[t]{2}{*}{ Auscultation of the heart } & Systolic/diastolic murmur without radiation & 57 & 14 \\
\hline & Systolic/diastolic murmur with radiation & 48 & 12 \\
\hline \multicolumn{4}{|l|}{ Locomotor system } \\
\hline \multirow[t]{5}{*}{ Orthopedic screening } & Limited stability at rest & 193 & 46 \\
\hline & Limited stability during walking & 177 & 42 \\
\hline & Limited mobility hip(s) & 152 & 37 \\
\hline & Limited mobility knee(s) & 105 & 25 \\
\hline & Limited mobility ankle(s) & 50 & 12 \\
\hline \multirow[t]{2}{*}{ Tandem gait } & Tandem gait score $\geq 40$ & 32 & 8 \\
\hline & Not possible, because of lack of stability & 115 & 28 \\
\hline \multirow[t]{2}{*}{ The timed up-and-go test } & Abnormal ( $\geq 20 \mathrm{sec})$ & 71 & 17 \\
\hline & Not possible, because of lack of stability & 3 & 1 \\
\hline \multicolumn{4}{|l|}{ Neurological system } \\
\hline \multirow[t]{3}{*}{ Tendon reflexes } & Abnormal patellar tendon reflex & 89 & 21 \\
\hline & Abnormal Achilles tendon reflex & 68 & 16 \\
\hline & Abnormal plantar responses & 9 & 2 \\
\hline \multirow{3}{*}{$\begin{array}{l}\text { Semmes-Weinstein mono- } \\
\text { filament test }\end{array}$} & $25 \%-50 \%$ disturbed & 65 & 16 \\
\hline & $50 \%-75 \%$ disturbed & 62 & 15 \\
\hline & $>75 \%$ disturbed & 80 & 19 \\
\hline \multicolumn{4}{|l|}{ Vestibular system } \\
\hline \multirow[t]{3}{*}{ Otoscopy } & Otitis media/externa & 7 & 2 \\
\hline & Perforated tympanic membrane & 13 & 3 \\
\hline & $\begin{array}{l}\text { Deformities tympanic membrane/inner ear } \\
\text { caused by trauma or surgery }\end{array}$ & 7 & 2 \\
\hline \multirow[t]{2}{*}{ Dix-Hallpike maneuver } & Positive & 44 & 11 \\
\hline & Unknown ${ }^{b}$ & 31 & 7 \\
\hline \multicolumn{4}{|l|}{ Remaining tests } \\
\hline \multirow[t]{2}{*}{ Corrected visual acuity } & Abnormal (ODS $\leq 0.5$ [Snellen metric]) & 120 & 29 \\
\hline & Unknownc & 31 & 7 \\
\hline \multicolumn{4}{|l|}{ Additional tests } \\
\hline \multicolumn{4}{|l|}{ Cardiovascular system } \\
\hline \multirow[t]{7}{*}{ Electrocardiogram } & Atrial fibrillation (known) & 13 & 3 \\
\hline & Atrial fibrillation (new) & 5 & 1 \\
\hline & Bradycardia & 7 & 2 \\
\hline & Premature ventricular complexes in bigeminy & 1 & 0 \\
\hline & Tachycardia (>100/min) & 1 & 0 \\
\hline & Third-degree atrioventricular block & 2 & 0 \\
\hline & Not indicated ${ }^{d}$ & 107 & 26 \\
\hline Continuous-loop event & Bradycardia & 1 & 0 \\
\hline recording & Sick sinus & 1 & 0 \\
\hline & Tachycardia (>100/min) & 2 & 0 \\
\hline & Premature ending by the patient & 3 & 1 \\
\hline & $\begin{array}{l}\text { Premature ending because of allergic } \\
\text { response to electrodes }\end{array}$ & 4 & 1 \\
\hline & Premature ending for other medical reason(s) & 3 & 1 \\
\hline & Not registerede & 357 & 86 \\
\hline
\end{tabular}




\begin{tabular}{|c|c|c|c|}
\hline Examination by System & Findings & No. & $\%$ \\
\hline \multicolumn{4}{|l|}{ Additional tests (continued) } \\
\hline \multicolumn{4}{|l|}{ Cardiovascular system (continued) } \\
\hline \multicolumn{4}{|l|}{ Laboratory tests } \\
\hline \multirow[t]{2}{*}{ Hemoglobin } & Moderately severe anemia & 5 & 1 \\
\hline & Severe anemia & 3 & 1 \\
\hline Nonfasting blood glucose & Hyperglycemia & 7 & 2 \\
\hline \multicolumn{4}{|l|}{ Psychiatric testing } \\
\hline \multirow{9}{*}{$\begin{array}{l}\text { PRIME-MD Patient Health } \\
\text { Questionnaire }\end{array}$} & One or more of listed diagnoses & 174 & 42 \\
\hline & Major depressive disorder & 53 & 13 \\
\hline & Other depressive disorder & 60 & 14 \\
\hline & Panic disorder & 19 & 5 \\
\hline & Other anxiety disorder & 42 & 10 \\
\hline & Any somatoform disorder & 89 & 21 \\
\hline & Probable alcohol abuse/dependence & 10 & 2 \\
\hline & Any eating disorder & 3 & 1 \\
\hline & Unknown & 2 & 0 \\
\hline \multicolumn{4}{|l|}{ Vestibular system } \\
\hline Audiometry & Abnormal audiogram both ears & 199 & 48 \\
\hline \multicolumn{4}{|c|}{ ODS = oculi dexter et sinister; PRIME-MD = Primary Care Evaluation of Mental Disorders. } \\
\hline \multicolumn{4}{|c|}{$\begin{array}{l}\text { Note: For diagnostic criteria, see Supplemental Appendix 2, available at http://www.annfammed.org/cgi/ } \\
\text { content/full/8/3/196/DC1. }\end{array}$} \\
\hline \multicolumn{4}{|c|}{ a Not measured because of edema, severe obesity, or irregular pulse. } \\
\hline \multicolumn{4}{|c|}{$\begin{array}{l}\text { b Not performed because of fear, pathology of neck or back, or other physical problems of the patient. } \\
\text { c Unreliable test result because of suboptimal testing conditions during home visit. }\end{array}$} \\
\hline \multicolumn{4}{|c|}{$\begin{array}{l}\text { An electrocardiogram was indicated if (1) a patient complained of presyncopal dizziness (a faint feeling, } \\
\text { light-headedness, or a feeling of everything turning black), (2) palpitations were associated with dizziness, or } \\
\text { (3) exercise provoked complaints of dizziness. }\end{array}$} \\
\hline \multicolumn{4}{|c|}{$\begin{array}{l}\text { e Continuous-loop event recording indicated if electrocardiogram did not show a clear explanation. } \\
\text { Questionnaire incomplete. }\end{array}$} \\
\hline
\end{tabular}

studies vary markedly in the reported prevalence of diagnoses, ${ }^{6,43}$ and an important phenomenon is revealed: investigators tend to diagnose conditions that they know about or are interested in. Sloane referred to this phenomenon as the blind men and the elephant. ${ }^{50}$ For example, Colledge et al performed magnetic resonance imaging of the head and neck and reported an unusually high prevalence of cervical spondylosis (66\%) as a cause of dizziness. ${ }^{49}$ In the present study we have tried to reduce the impact of such a phenomenon by using experts from 8 different medical disciplines (cardiology, otolaryngology, family practice, geriatric medicine, internal medicine, neurology, nursing home medicine, and rehabilitation medicine $)^{20}$ for the selection of diagnostic tests and by using clinicians from 3 different medical disciplines (geriatric medicine, family practice, and nursing home medicine) for independent review of the data.

\section{Strengths and Limitations}

A strength of this study is the selection of our population. The population in the our study is highly representative of family practice, which is partly due to the monthly database search for patients whom the family physicians had failed to invite. No other diagnostic study on dizziness used this method to prevent selective inclusion.

Another strength is that, contrary to previous studies, we used an international Delphi procedure for the selection of diagnostic tests. ${ }^{20}$

A further strength is that we used panel diagnosis to identify contributory causes of dizziness. This research method is well suited if a generally accepted reference standard does not exist and multiple sources of information have to be interpreted in a judicious way to reach a diagnosis. In particular, the panel method is suited for conditions that cannot unequivocally be defined. ${ }^{40}$ Most previous diagnostic studies on dizziness used a single clinician for determining cause and were therefore more susceptible to investigator bias.

Some limitations of our study should be mentioned. First, the absence of a clinical follow-up as an additional source of information might be regarded as a limitation. ${ }^{40}$ For that reason, we have initiated a follow-up study among our study population. We emphasize, however, that a follow-up study will not solve the fundamental problem of diagnostic research on dizziness: most diagnoses related to dizziness in family practice lack a reliable reference standard ${ }^{51}$ so often it is impossible to confirm a suspected cause of dizziness.

Second, despite our attempt to see more of the "elephant,"50 our study may have diagnostic blind spots, both on the level of test selection (ie, some diagnostic tests may be absent as a result of preferences of the experts participating in the Delphi procedure) ${ }_{1}^{20}$ and on the level of test interpretation (ie, panel members' preferences might cause some diagnoses may to be understated or overrated).

Third, the relatively low levels of interrater agreement ( $\kappa$ and ICC of 0.1-0.4) suggest discordant disease classification. ${ }^{40}$ Such a degree of clinical disagreement was to be expected (Kroenke et al found an overall $\kappa$ of 0.39$),{ }^{9}$ because dizziness is a symptom that may have a multifactorial origin, especially in the elderly. It is for this reason that we used a panel of 3 clinicians 
representing different, yet relevant, general medical disciplines and that we combined their assessments according to additional, well-defined decision rules. The relatively low levels of interrater agreement also

\begin{tabular}{|c|c|c|}
\hline Characteristic & No. & $\%$ \\
\hline \multicolumn{3}{|l|}{ Dizziness subtype ${ }^{a}$} \\
\hline Presyncope & 288 & 69 \\
\hline Vertigo & 171 & 41 \\
\hline Disequilibrium & 166 & 40 \\
\hline Other dizziness & 7 & 2 \\
\hline No consensus & 16 & 4 \\
\hline Total & 648 & \\
\hline \multicolumn{3}{|c|}{ Number of dizziness subtypes per patient } \\
\hline 1 & 217 & 52 \\
\hline 2 & 137 & 33 \\
\hline 3 & 47 & 11 \\
\hline No consensus & 16 & 4 \\
\hline Total & 417 & 100 \\
\hline \multicolumn{3}{|c|}{$\begin{array}{l}\text { Note: Data for each patient were independently reviewed by a family physi- } \\
\text { cian, a geriatrician, and a nursing home doctor. }\end{array}$} \\
\hline \multicolumn{3}{|c|}{$\begin{array}{l}\text { adds up to more than } 100 \% \text {, because more than } 1 \text { dizziness subtype per } \\
\text { patient is possible. }\end{array}$} \\
\hline
\end{tabular}

\section{Table 5. Causes of Dizziness in 417 Elderly Patients in Primary Care (Panel Diagnosis)}

\begin{tabular}{|c|c|c|c|c|c|c|}
\hline \multirow[b]{2}{*}{ Characteristic } & \multicolumn{2}{|c|}{ Major Cause } & \multicolumn{2}{|c|}{ Minor Cause } & \multicolumn{2}{|c|}{ Total ${ }^{a}$} \\
\hline & No. & $\%$ & No. & $\%$ & No. & $\%$ \\
\hline \multicolumn{7}{|l|}{ Contributing causes } \\
\hline Adverse drug effect & 10 & 2 & 96 & 23 & 106 & 25 \\
\hline $\begin{array}{l}\text { Cardiovascular disease (including } \\
\text { cerebrovascular disease) }\end{array}$ & 237 & 57 & 66 & 16 & 303 & 73 \\
\hline Locomotor disease & 15 & 4 & 43 & 10 & 58 & 14 \\
\hline Metabolic or endocrine conditions & 3 & 1 & 3 & 1 & 6 & 1 \\
\hline $\begin{array}{l}\text { Neurological disease (excluding } \\
\text { cerebrovascular disease) }\end{array}$ & 12 & 3 & 36 & 9 & 48 & 12 \\
\hline Psychiatric illness & 41 & 10 & 40 & 10 & 81 & 19 \\
\hline Peripheral vestibular disease & 60 & 14 & 40 & 10 & 100 & 24 \\
\hline Impaired vision & 2 & 0 & 3 & 1 & 5 & 1 \\
\hline Other causes & 3 & 1 & 4 & 1 & 7 & 2 \\
\hline Unclear & 34 & 8 & - & - & 34 & 8 \\
\hline Total & 417 & 100 & 331 & 79 & 748 & 179 \\
\hline \multicolumn{7}{|l|}{ Contributing causes per patient } \\
\hline 1 & 126 & 30 & & & & \\
\hline 2 & 191 & 46 & & & & \\
\hline 3 & 59 & 14 & & & & \\
\hline 4 & 6 & 1 & & & & \\
\hline 5 & 1 & 0 & & & & \\
\hline Unclear & 34 & 8 & & & & \\
\hline Total & 417 & 100 & & & & \\
\hline \multicolumn{7}{|c|}{$\begin{array}{l}\text { Note: Data for each patient were independently reviewed by a family physician, a geriatrician, and a nursing } \\
\text { home doctor. }\end{array}$} \\
\hline
\end{tabular}

illustrate that individual clinicians may have diagnostic preferences. Accordingly, as do Kroenke et al ${ }_{1}^{9}$ we believe that multiple raters should be used in symptom research to counterbalance investigator bias.

Fourth, it may seem advisable to extend the panel to include clinicians from other medical disciplines, such as cardiology, otolaryngology, or neurology. Because the data were drawn from a nonreferred, family practice population, however, we chose to select clinicians from disciplines with a generalistic approach toward dizziness.

Fifth, there appears to be a discrepancy between the results of physical examination/additional diagnostic tests (Table 3), and the final distribution of contributing causes of dizziness (Table 5). For example, contrary to the relatively low frequency of abnormal findings during cardiovascular testing, our panel considered cardiovascular disease to be the most common cause of dizziness. This discrepancy may be because the panel members considered the clinical history to be the key diagnostic tool $1^{5,9}$ and (sometimes) superior to the results of physical examination and additional diagnostic tests.

Sixth, it is possible that the semantic and cultural meanings of the word "dizziness" may differ in Dutch and English, which can affect the results of the study. The data of a recently performed study, ${ }^{52}$ however, suggest that the symptoms of Dutch dizzy patients match well with the widely used symptom classification of Drachman and Hart. ${ }^{15}$

Finally, another panel may assess the data differently, especially if such a panel has a different educational, cultural, or other background. We therefore want to use our data in a future case vignette study to assess the generalizability of the diagnoses made by our panel.

\section{Implications for Clinical Practice}

Understanding the clinical epidemiology of dizziness in its corresponding population is an essential first step when evaluating dizziness. ${ }^{50}$ Although vestibular disease is considered to be the most common cause of dizziness in secondary or tertiary care, the results of our 
study suggest that cardiovascular disease is the most common cause of dizziness in elderly patients in primary care.

In daily clinical practice, family physicians should anticipate that many dizzy elderly patients have more than 1 cause of dizziness. A systematic exploration of dizziness may find contributory causes that are amenable to treatment, such as an adverse drug effect that can be resolved by adjusting medication, depression or anxiety that might be amenable to psychotherapy, limited stability during walking that can be improved with physiotherapy/balance training, or impaired vision that can be corrected. An approach that considers multiple causes of dizziness in elderly patients may, if not solve the problem of dizziness, lead to a clinically relevant reduction of impairments that contribute to dizziness.

To read or post commentaries in response to this article, see it online at http://www.annfammed.org/cgi/content/full/8/3/196.

Key words: Dizziness, diagnosis; primary care; family practice; elderly

Submitted August 10, 2009; submitted, revised, November 24, 2009; accepted December 3, 2009.

Author contributions: H.vdH. and H.vW. obtained funding for the study. O.R.M., J.D., F.G.S., H.C.vW., D.A.vdW., G.tR., and H.E.vdH. were involved in the design of the study. O.R.M. performed the statistical analysis and wrote the original draft. All authors critically revised the draft for intellectual content and approved the final version.

Funding support: This study was supported by the Netherlands Organisation for Health Research and Development (ZonMW, No. 4200.0018), The Hague. The sponsor did not participate in the study design, data collection, analysis, interpretation, or the preparation or submission of this report.

Portions of this article have been presented at the Dizziness Conference Garderen, The Netherlands, May 2009; and the European General Practice Research Network, Dubrovnik, Croatia, October 2009.

Acknowledgments: The authors wish to thank Professor Patrick J. Bindels for his assistance with the design of the study, and Patria M. Diaz Nerio, Sophie Hengst, and Astrid Wewerinke for their assistance with the examination of patients.

\section{References}

1. Jönsson R, Sixt E, Landahl S, Rosenhall U. Prevalence of dizziness and vertigo in an urban elderly population. J Vestib Res. 2004;14(1): 47-52.

2. Tinetti ME, Williams CS, Gill TM. Dizziness among older adults: a possible geriatric syndrome. Ann Intern Med. 2000;132(5):337-344.

3. Colledge NR, Wilson JA, Macintyre CC, MacLennan WJ. The prevalence and characteristics of dizziness in an elderly community. Age Ageing. 1994;23(2):117-120.

4. Sloane P, Blazer D, George LK. Dizziness in a community elderly population. J Am Geriatr Soc. 1989;37(2):101-108.

5. Sloane PD, Baloh RW. Persistent dizziness in geriatric patients. J Am Geriatr Soc. 1989;37(11):1031-1038.
6. Sloane PD, Coeytaux RR, Beck RS, Dallara J. Dizziness: state of the science. Ann Intern Med. 2001;134(9 Pt 2):823-832.

7. Lawson J, Fitzgerald J, Birchall J, Aldren CP, Kenny RA. Diagnosis of geriatric patients with severe dizziness. J Am Geriatr Soc. 1999; 47(1):12-17.

8. Madlon-Kay DJ. Evaluation and outcome of the dizzy patient. J Fam Pract. 1985;21(2):109-113.

9. Kroenke K, Lucas CA, Rosenberg ML, et al. Causes of persistent dizziness. A prospective study of 100 patients in ambulatory care. Ann Intern Med. 1992;117(11):898-904.

10. Sloane PD. Dizziness in primary care. Results from the National Ambulatory Medical Care Survey. J Fam Pract. 1989;29(1):33-38.

11. Okkes IM, Oskam SK, Lamberts H. From Complaint to Diagnosis. Episode Data From Family Practice. Bussum,The Netherlands: Coutinho; 1998.

12. Herr RD, Zun L, Mathews JJ. A directed approach to the dizzy patient. Ann Emerg Med. 1989;18(6):664-672.

13. Newman-Toker DE, Hsieh YH, Camargo CA Jr, Pelletier AJ, Butchy GT, Edlow JA. Spectrum of dizziness visits to US emergency departments: cross-sectional analysis from a nationally representative sample. Mayo Clin Proc. 2008;83(7):765-775.

14. Davis LE. Dizziness in elderly men. J Am Geriatr Soc. 1994;42(11): 1184-1188

15. Drachman DA, Hart CW. An approach to the dizzy patient. Neurology. 1972;22(4):323-334

16. Katsarkas A. Dizziness in aging: a retrospective study of 1194 cases. Otolaryngol Head Neck Surg. 1994;110(3):296-301.

17. Nedzelski JM, Barber HO, Mcllmoyl L. Diagnoses in a dizziness unit. J Otolaryngol. 1986;15(2):101-104.

18. Uneri A, Polat S. Vertigo, dizziness and imbalance in the elderly. J Laryngol Otol. 2008;122(5):466-469.

19. Katsarkas A. Dizziness in aging: the clinical experience. Geriatrics. 2008;63(11):18-20.

20. Maarsingh OR, Dros J, Van Weert HC, Schellevis FG, Bindels PJ, Van der Horst HE. Development of a diagnostic protocol for dizziness in elderly patients in general practice: a Delphi procedure. BMC Fam Pract. 2009;10:12. http://www.biomedcentral.com/1471-2296/10/12.

21. Veehof L, Stewart R, Haaijer-Ruskamp F, Jong BM. The development of polypharmacy. A longitudinal study. Fam Pract. 2000;17(3): 261-267.

22. van der Velde N, Stricker BH, Pols HA, van der Cammen TJ. Risk of falls after withdrawal of fall-risk-increasing drugs: a prospective cohort study. Br J Clin Pharmacol. 2007;63(2):232-237.

23. Persoons P, Luyckx K, Desloovere C, Vandenberghe J, Fischler B. Anxiety and mood disorders in otorhinolaryngology outpatients presenting with dizziness: validation of the self-administered PRIME-MD Patient Health Questionnaire and epidemiology. Gen Hosp Psychiatry. 2003;25(5):316-323.

24. Spitzer RL, Williams JB, Kroenke K, et al. Utility of a new procedure for diagnosing mental disorders in primary care. The PRIME-MD 1000 study. JAMA. 1994;272(22):1749-1756.

25. Jacobson GP, Newman CW. The development of the Dizziness Handicap Inventory. Arch Otolaryngol Head Neck Surg. 1990;116(4):424-427.

26. Atkins D, Hanusa B, Sefcik T, Kapoor W. Syncope and orthostatic hypotension. Am J Med. 1991;91(2):179-185.

27. Brignole M, Alboni P, Benditt DG, et al.; Task Force on Syncope, European Society of Cardiology. Guidelines on management (diagnosis and treatment) of syncope-update 2004. Europace. 2004; $6(6): 467-537$

28. Hoefman E, van Weert HC, Boer KR, Reitsma J, Koster RW, Bindels PJ. Optimal duration of event recording for diagnosis of arrhythmias in patients with palpitations and light-headedness in the general practice. Fam Pract. 2007;24(1):11-13 
29. Brinkman DMC, Kuipers-Upmeijer J, Oosterhuis HJGH. [Quantification and evaluation of 5 neurological equilibrium tests in test subjects and patients]. Ned Tijdschr Geneeskd. 1996;140(44):2176-2180.

30. Podsiadlo D, Richardson S. The timed "Up $\varepsilon$ Go": a test of basic functional mobility for frail elderly persons. J Am Geriatr Soc. 1991; 39(2):142-148.

31. Boulton AJ, Vinik Al, Arezzo JC, et al.; American Diabetes Association. Diabetic neuropathies: a statement by the American Diabetes Association. Diabetes Care. 2005;28(4):956-962.

32. NHS National Institute for Clinical Excellence (NICE). Type 2 Diabetes Prevention and Management of Foot Problems, Clinical Guideline 10. London: NICE; 2004

33. Singh N, Armstrong DG, Lipsky BA. Preventing foot ulcers in patients with diabetes. JAMA. 2005;293(2):217-228

34. Furman JM, Cass SP. Benign paroxysmal positional vertigo. N Engl J Med. 1999;341(21):1590-1596.

35. Dix MR, Hallpike CS. The pathology, symptomatology and diagnosis of certain common disorders of the vestibular system. Ann Otol Rhinol Laryngol. 1952;61(4):987-1016.

36. Fife TD, Tusa RJ, Furman JM, et al. Assessment: vestibular testing techniques in adults and children: report of the Therapeutics and Technology Assessment Subcommittee of the American Academy of Neurology. Neurology. 2000;55(10):1431-1441.

37. Eekhof JAH, Ek JW, Van Weert HCPM, Spies TH, Hufman PW, Hoftijzer NP. The guideline 'Hearing impairment' of the Dutch College of General Practitioners. Huisarts Wet. 1997;40:70-78

38. Van Wijk MAM, Mel M, Muller PA, Silverentand WGJ, Pijnenborg L, Kolnaar BGM. The guideline 'Anemia' of the Dutch College of General Practitioners. Huisarts Wet. 2003;43(1):21-29.

39. Rutten GEHM, De Grauw WJC, Nijpels G, et al. The practice guideline 'Diabetes mellitus type 2 (second revision)' of the Dutch College of General Practitioners. Huisarts Wet. 2006;49(3):137-152.

40. Rutjes AW, Reitsma JB, Coomarasamy A, Khan KS, Bossuyt PM. Evaluation of diagnostic tests when there is no gold standard. A review of methods. Health Technol Assess 2007 December;11(50):iii, ix-51.
41. Baloh RW. Vertigo. Lancet. 1998;352(9143):1841-1846.

42. Benditt DG, van Dijk JG, Sutton R, et al. Syncope. Curr Probl Cardiol. 2004;29(4):152-229.

43. Hoffman RM, Einstadter D, Kroenke K. Evaluating dizziness. Am J Med. 1999;107(5):468-478.

44. Geertzen J. Cohen's Kappa for more than two annotators with multiple classes. http://cosmion.net/jeroen/software/kappa/\#demo.

45. McGraw KO, Wong SP. Forming inferences about some intraclass correlation coefficients [published erratum appears in Psychological Methods 1996; 1(4):390]. Psychol Methods. 1996;1(1):30-46.

46. Koch GG, Landis JR, Freeman JL, Freeman DH Jr, Lehnen RC. A general methodology for the analysis of experiments with repeated measurement of categorical data. Biometrics. 1977;33(1):133-158.

47. Hanley K, O' Dowd T. Symptoms of vertigo in general practice: a prospective study of diagnosis. Br J Gen Pract. 2002;52(483):809-812.

48. Sloane PD, Dallara J, Roach C, Bailey KE, Mitchell M, McNutt R. Management of dizziness in primary care. J Am Board Fam Pract. $1994 ; 7(1): 1-8$

49. Colledge NR, Barr-Hamilton RM, Lewis SJ, Sellar RJ, Wilson JA. Evaluation of investigations to diagnose the cause of dizziness in elderly people: a community based controlled study. BMJ. 1996; 313(7060):788-792

50. Sloane PD, Dallara J. Clinical research and geriatric dizziness: the blind men and the elephant. J Am Geriatr Soc. 1999;47(1):113-114.

51. Dros J, Maarsingh OR, Van der Horst HE, Bindels PJ, Ter Riet G, Van Weert HCPM. Dizziness in primary care: a systematic review of diagnostic tests. CMAJ 2010. In press.

52. Maarsingh OR, Dros J, Schellevis FG, Van Weert HCPM, Bindels PJ, Van der Horst HE. Dizziness reported by older patients in family practice: prevalence, incidence, and clinical characteristics. BMC Fam Pract. 2010;11(1):2. 